\title{
Atividade de estudo como conceito central para a psicologia escolar
}

\author{
Study activity as a central concept for school psychology
}

\author{
Flávia da Silva Ferreira Asbahr ${ }^{1}$ \\ Ana Bárbara Joaquim Mendonça ${ }^{2}$
}

\begin{abstract}
RESUMO
A Psicologia Escolar em uma perspectiva crítica, historicamente, buscou superar a culpabilização dos estudantes frente às dificuldades de aprendizagem e compreender o processo de escolarização em suas múltiplas determinações. No entanto, avalia-se que a fim de não permanecermos apenas no lugar da crítica e da denúncia ao fracasso escolar, necessitamos também desenvolver teórica e praticamente meios que possam instrumentalizar uma atuação propositiva. Dessa forma, este ensaio visa apresentar a atividade de estudo enquanto um conceito fundamental à atuação da/o psicóloga/o escolar que se orienta a partir da Psicologia Histórico-Cultural. Para tanto, busca inicialmente justificar a necessidade do conceito e, em um segundo momento, apresentar o que é atividade de estudo, como esta se forma e se estrutura. Por fim, propõe-se a articular este conceito com a atuação da Psicologia Escolar.
\end{abstract}

Palavras-chave: Psicologia Escolar. Atividade de estudo. Psicologia Histórico-Cultural.

\begin{abstract}
A critical perspective of School Psychology, historically, sought to overcome the blaming of students that have been through learning difficulties and seeks to understand the schooling process in its multiple determinations. However, in order to not only remain in the place of criticism and denunciation of academic failure, we also need to develop theoretical and practical elements that can instrumentalize an acting with a clear proposal. Thus, this essay aims to present the study activity as a fundamental concept to the work of the school psychologist, guided by Historical-Cultural Psychology. Therefore, it initially seeks to justify the necessity for the concept and, in a second moment, introduce the study activity, especially how it is formed and structured. Finally, aims to articulate this concept with the work of School Psychology.
\end{abstract}

Keywords: School Psychology. Study activity. Historical-Cultural Psychology.

\section{Introdução}

O artigo, de natureza teórica, tem como objetivo problematizar as seguintes questões: Por que e para quê discutir sobre a atividade de estudo no âmbito da atuação da psicologia escolar? Temos defendido, enquanto professoras

\footnotetext{
${ }^{1}$ Professora assistente do Departamento de Psicologia e do Programa de Pós-Graduação em Psicologia do Desenvolvimento e Aprendizagem, da Faculdade de Ciências, UNESP-Bauru. ORCID: https://orcid.org/0000-0002-7338-0003. Email: flavia.asbahr@unesp.br.

${ }^{2}$ Doutoranda do Programa de Pós-Graduação em Psicologia do Desenvolvimento e Aprendizagem, da Faculdade de Ciências, UNESP-Bauru. Professora substituta do Departamento de Psicologia (FCUNESP-Bauru). ORCID: https://orcid.org/0000-0001-5921-380X. Email: ana.barbara@unesp.br.
} 
da disciplina Psicologia Escolar e supervisoras do estágio na mesma área, que a atividade de estudo é conceito fundamental à atuação da psicologia escolar fundamentada na psicologia histórico-cultural.

Para responder estas questões precisamos, primeiramente, fazer uma breve análise sobre a constituição histórica da psicologia escolar em uma perspectiva crítica, buscando entender seus avanços, mas também propondo algumas discussões as quais avaliamos ser necessárias desenvolver para não corrermos o risco de permanecer no lugar da crítica e da denúncia às concepções hegemônicas sobre o fracasso escolar, mas sem ter elementos teórico-práticos que possam instrumentalizar uma atuação propositiva e desenvolvente na educação escolar. Esta temática é explorada na primeira parte do artigo.

$\mathrm{Na}$ segunda parte do texto, focaremos a definição do que é atividade de estudo, como esta se forma e se estrutura, apresentando um panorama geral sobre a atividade principal da criança em idade escolar e trazendo elementos que anunciam a atividade de estudo como conceito central para a psicologia escolar crítica baseada teoricamente na psicologia histórico-cultural.

Por fim, tomando como premissa que a psicologia escolar deve estar direcionada para que a escola cumpra sua função social de garantir que todas as crianças tenham acesso ao conhecimento elaborado (MEIRA, 2003), encerramos o texto com algumas breves considerações sobre as possibilidades de atuação da/o psicóloga/o na educação.

Ressalta-se que o artigo caracteriza-se como ensaio teórico (MENEGHETTI, 2011) e procura articular discussões teóricas na intersecção entre os estudos da psicologia escolar crítica e a teoria histórico cultural sem a pretensão de trazer uma revisão sistemática da literatura.

\section{Psicologia escolar crítica: por que o conceito de atividade de estudo é necessário?}

Historicamente, um dos primeiros campos que a Psicologia explorou em seu processo de tornar-se ciência, ainda no final do século XIX, foi a Educação, com investigações que buscavam explicar e justificar as denominadas 
dificuldades de aprendizagem. Patto (1999), em seu clássico "A produção do fracasso escolar: histórias de submissão e rebeldia”, apresenta um crítico panorama histórico de quais foram as principais concepções e ideias acerca do fracasso escolar produzidas do final do século XIX até os anos setenta do século XX. Segundo a autora, seu objetivo foi reconstituir a gênese destas ideias a partir de seu contexto histórico, social e político. Patto (1999) defende que para compreender o fracasso escolar é preciso reunir informações sobre a filiação histórica das ideias (crenças, certezas científicas) sobre a pobreza e seus reveses, o que inclui a dificuldade de escolarização.

Patto (1999) reconstrói, assim, quais foram as principais concepções sobre as dificuldades de aprendizagem, partindo das teorias raciais até chegar à teoria da carência cultural, passando também pelos modelos clínicos, orgânicos e psicométricos. Em comum, todas essas explicações colocam na criança, em sua família, ou no máximo no ambiente dos alunos, as causas das supostas dificuldades de aprendizagem. A Psicologia hegemônica contribui, assim, com a pedagogia da exclusão, ao classificar e rotular as pessoas, selando seus destinos e servindo para justificar as desigualdades sociais (ASBAHR; LOPES, 2006).

Foge aos objetivos deste texto apresentar um panorama mais aprofundado das diferentes explicações individualizantes e ideológicas que vem sendo utilizadas para explicar porque muitas crianças, especialmente os alunos das camadas populares matriculados na escola pública, não aprendem. Sobre o tema, recomendamos a leitura da própria Patto (1981; 1999), da também clássica obra organizada por Souza e Machado (1997), do livro organizado por Facci, Meira e Tuleski (2011) e do texto de Tanamachi e Meira (2003), em que as autoras apresentam um quadro-síntese com as principais concepções teóricas tradicionais sobre o fracasso escolar.

Críticas contundentes têm sido realizadas, há algumas décadas, a essas concepções de fracasso que partem de uma visão preconceituosa dos pobres e negros e representa valores e ideias da classe dominante. Desde o final dos anos 80 e mais especificamente a partir dos anos 90, vemos no Brasil o esforço para construir uma psicologia com olhar e atuação em uma perspectiva crítica na educação escolar 
(SOUZA, 2000; MEIRA, 2000; TANAMACHI, 2000; MACHADO, 2000; FACCI, 2004; FACCI, ANACHE; CALDAS, 2021; entre outros inúmeros trabalhos).

Este movimento de crítica à psicologia escolar hegemônica, conhecido de forma geral como psicologia escolar crítica, buscou superar a histórica culpabilização dos alunos em relação aos problemas escolares e compreender o processo de escolarização em suas múltiplas determinações. Nesse sentido, o objeto de análise e intervenção da Psicologia Escolar em uma perspectiva crítica é "o encontro entre o sujeito humano e a educação" (MEIRA, 2000, p. 58).

Tal concepção de psicologia compreende a escola como instituição que está inserida em uma sociedade de classes, o que requer, para que se possa analisar o encontro entre os sujeitos e a educação, um exame do papel da escola nesta sociedade (SAVIANI, 2008). Dentre as principais contribuições da psicologia escolar crítica à educação, podemos destacar a análise da instituição e da qualidade do processo educacional, o que inclui a compreensão dos impactos das políticas públicas educacionais no cotidiano escolar; o foco no processo de escolarização de forma mais ampla e não apenas nas dificuldades de aprendizagem; a interface com outras áreas das ciências humanas além da psicologia.

Avaliamos que, em termos de concepção sobre os fenômenos escolares, temos avanços importantes na psicologia escolar. Nas pesquisas sobre atuação de psicólogas/os escolares (SOUZA; SILVA; YAMAMOTO, 2014) é cada vez mais comum encontrarmos a reprodução de discursos críticos sobre a medicalização, sobre a produção do fracasso escolar, sobre a superação do modelo clínico de atuação, sobre as relações entre educação e sociedade. Não raro são citados autores como Maria Helena Souza Patto, Marilene Proença Rebello de Souza, Beatriz de Paula Souza, Paulo Freire, Demerval Saviani, Lev Vigotski, entre outros. No entanto, quando o foco é o relato da atuação profissional, embora também tenhamos avanços na perspectiva da construção de práticas críticas, ainda há a expectativa de que a atuação da psicologia na escola seja avaliar e atender individualmente às crianças que apresentam dificuldades no processo de 
escolarização. Ou seja, a representação social da/o profissional psicóloga/o para professoras/es ainda está centrada no modelo clínico.

Mesmo quando há uma compreensão mais ampla sobre as possibilidades de atuação da psicologia na escola, por exemplo, no campo da formação de professores, a análise crítica sobre a produção do fracasso e demais fenômenos escolares não nos parece suficiente. Docentes compreendem as críticas às visões biologizantes ou medicalizantes sobre o fracasso escolar, mas continuam sem instrumentos para pensar e atuar diante de crianças que têm dificuldades "crônicas" de aprendizagem. Ou, entendem o caráter multideterminado da produção do fracasso escolar, mas tal análise não instrumentaliza o/a professor/a para que possa construir estratégias pedagógicas produtoras de aprendizagem e desenvolvimento e minimizar o sofrimento da criança que não está aprendendo.

Neste sentido, concordamos com as proposições de Tanamachi e Meira (2003, p. 23) segundo as quais uma teoria crítica não pode apenas descrever ou explicar como e porque um fenômeno ocorre, mas precisa trazer elementos para pensar quais são as possibilidades de transformação do mesmo:

[...] mediações teóricas não podem apenas explicar como e porque os indivíduos agem ou são de uma ou de outra maneira, mas deverão também buscar responder como e porque os indivíduos podem vir a agir ou tornarem-se seres emancipados (TANAMACHI; MEIRA, 2003, p. 23).

E é aí que entra a Psicologia Histórico-Cultural como teoria da psicologia que busca não apenas descrever como os fenômenos psicológicos são produzidos histórico e culturalmente, mas também como abordagem que se propõe a explicar o desenvolvimento humano de forma prospectiva, no seu vir-a-ser. Parafraseando Marx (1845/2020), em sua $11^{\mathrm{a}}$ tese sobre Feuerbach, nós, psicólogos, temos interpretado os processos de escolarização, desenvolvimento e de aprendizagem de maneiras diferentes; a questão, porém, é transformar estes processos tomando como referência a máxima de Vigotski (1988) de que o único bom ensino é o que se adianta ao desenvolvimento. 
Dessa forma, dentre as diversas teorias psicológicas que buscam compreender os fenômenos escolares de forma crítica, assinala-se que o escopo teórico-conceitual adotado no presente trabalho é a Psicologia Histórico-Cultural, a qual se apoia filosófica e epistemologicamente no Materialismo Histórico de Karl Marx. Esta abordagem, nascida no contexto da revolução comunista soviética de 1917, inicia-se com os trabalhos de Lev Sememovich Vigotski ${ }^{3}$ (18961934) e do grupo conhecido como Troika, composto por Alexander Romanovich Luria (1902--1977) e Alexei Nikolaievich Leontiev (1903--1979).

Além da troika, desde a década de 1920 do século XX, o projeto de construir uma Psicologia Histórico-Cultural, de fundamentação marxista, reuniu outros pesquisadores que estudavam diferentes temáticas e que, ao longo dos anos, distribuíram-se em várias universidades da ex-URSS. Alguns dos integrantes dessa escola são Daniil Borisovich Elkonin (1904-1984), Piotr Iakovlevich Galperin (1902--1988), Bluma Vulfovna Zeigarnik (1900-1988), Alexander Vladimirovich Zaporozhets (1905-1981), Rosa Evgenevna Levina (1909-1989), Natalia Grigorievna Morozova (1906-1989), Lidia Ilinichna Bozhovich (1908-1981), Lia Solomonovna Slavina (1906-1986), Vasili Vasílievich Davidov (1930-1998), Boris Fedorovich Lomov (1927-1989), Piotr Ivanovich Zinchenko (1903-1969) e Sergey Leonidovich Rubinstein (1899-1960), entre muitos outros ${ }^{4}$.

$\mathrm{Na}$ busca de uma concepção crítica de psicologia e de educação, o encontro com a teoria histórico-cultural tem sido frutífero:

[...] cabe à Psicologia oferecer subsídios para o desenvolvimento de uma concepção científica do indivíduo, entendido como síntese da história social da humanidade, de cujo desenvolvimento deve conscientemente participar para assegurar sua emancipação. Trata-se de tomar como tarefa também da Psicologia o estabelecimento de mediações entre o desenvolvimento históricosocial da humanidade e a vida particular dos indivíduos (TANAMACHI; MEIRA, 2003, p. 22-23).

\footnotetext{
${ }^{3}$ Em português, aparecem várias grafias para Vigotski: Vygotski, Vygotsky, Vigotskii e outras.

${ }^{4}$ Recomendamos a obra de Shuare (2017), que apresenta um panorama histórico da psicologia soviética, e a trilogia organizada Andréa Maturano Longarezi e Roberto Valdés Puentes organizaram sobre a vida, pensamento e obra dos principais representantes russos da teoria histórico-cultural (LONGAREZI; PUENTES, 2013; PUENTES; LONGAREZI, 2016; PUENTES; LONGAREZI, 2019).
} 
A psicologia histórico-cultural traz um arcabouço teórico sólido e conceitos fundamentais para uma atuação crítica da/o psicóloga/o na escola. Partindo dos pressupostos de que o psiquismo tem caráter material e mediado, de que a atividade tem papel fundamental na constituição psíquica e de que os fenômenos psicológicos devem ser estudados dialeticamente (SHUARE, 2017), Vigotski define as funções psicológicas superiores como objeto de estudo da Psicologia e com a explicação da lei geral de sua formação, expressa, de forma contundente, sua concepção histórico-cultural de psiquismo. Ou seja, constrói os fundamentos de uma Psicologia que estuda os fenômenos verdadeiramente humanos, uma psicologia concreta do homem, nas palavras do próprio autor (VIGOTSKI, 2000).

São diversos os temas estudados por Vigotski e seus continuadores ${ }^{5}: 1$ ) as relac,ões entre desenvolvimento e aprendizagem e o conceito de Zona de desenvolvimento Iminente ${ }^{6}$; 2) as relacõoes entre pensamento e fala, incluindo a formação de conceitos; 3) as relações entre a formação da consciência, das emoções e das vivências; 4) estudos sobre o desenvolvimento da pessoa com deficiência, o que era conhecido na época como defectologia; 5) estudos no campo de pedologia, ciência interdisciplinar cujo foco era a compreensão do desenvolvimento infantil; 6) o desenvolvimento das funções psicológicas superiores; entre outros.

No âmbito deste texto, nos interessa a análise histórico-cultural sobre as relações entre desenvolvimento e aprendizagem, tendo como foco a periodização do desenvolvimento infantil. Vigotski (2012), em um texto intitulado "O problema da idade", escrito em 1932, avalia que a periodização do desenvolvimento é uma questão central para a Psicologia Histórico-Cultural.

O autor aponta a existência de uma rede subterrânea de processos no interior do psiquismo de cada estudante, que se desencadeia no próprio curso da aprendizagem (VIGOTSKI, 2009). Assim, entende que uma tarefa essencial da

\footnotetext{
${ }^{5}$ Não temos a pretensão de apresentar uma lista completa dos temas estudados por Vigotski, o que inclusive fugiria dos objetivos do presente artigo.

${ }^{6} \mathrm{O}$ conceito zona blijaichego razvitia tem sido traduzido para o português de maneiras diversas: zona de desenvolvimento próximo, proximal, potencial, imediato. Utilizaremos aqui a tradução de Prestes (2010), zona de desenvolvimento iminente.
} 
psicologia voltada ao campo educacional seria desvelar a lógica interna dos processos de aprendizagem. Com isso, ressalta-se a necessidade de clareza acerca do processo de desenvolvimento dos estudantes, já que tal compreensão torna possível refletir acerca dos processos de ensino.

Dessa forma, para compreender o processo de desenvolvimento da criança, mostra-se essencial o entendimento de sua periodização, ou seja, a definição dos períodos do desenvolvimento, bem como os processos de transição de um a outro. Vigotski (2012) realiza primeiramente um movimento de crítica acerca dos esquemas de periodização de sua época. Em sua avaliação, estes cometiam diversos erros metodológicos, que resultaram em análises rasas, meramente descritivas e baseadas em índices externos referentes a cada período. Diferentemente de tal posição, o autor salienta que a base para a periodização seria a própria reorganização do processo de desenvolvimento, tornando necessário investigar o que se oculta por trás dos diversos indícios, compreender o que os condiciona, ou seja, desvelar "o próprio processo de desenvolvimento infantil com suas leis internas" (VYGOTSKI, 2012, p. 253, tradução nossa). Assim sendo, o princípio que estrutura a periodização corresponde às trocas internas do próprio desenvolvimento, de modo que se torna fundamental a análise da dinâmica do desenvolvimento e a dinâmica das transições.

O desenvolvimento da criança não é outra coisa que a permanente passagem de um escalão evolutivo a outro, passagem ligada à mudança e à estruturação da personalidade da criança. Estudar o desenvolvimento infantil significa estudar a transição da criança de um degrau evolutivo a outro e a mudança de sua personalidade dentro de cada período evolutivo, que tem lugar em condições histórico-sociais concretas (VIGOTSKI, s/d, p. 5 apud ELKONIN, 2017, p. 152).

A partir disso, Vygotski (2012) sinaliza o caráter revolucionário do desenvolvimento humano. Conforme o autor explica, em determinadas etapas ocorre um curso lento, com trocas internas e quase imperceptíveis, que apenas serão exteriorizadas após um longo processo de desenvolvimento latente. Assim, ao se acumularem, estas se manifestam de forma repentina a partir de formações qualitativamente novas. Estes são os períodos de crise, nos quais se produzem 
modificações e rupturas na personalidade da criança. Dessa forma, em cada período a personalidade da criança se modifica como um todo.

O que se apreende subsequentemente é que o desenvolvimento deve ser compreendido a partir de um enfoque histórico e a partir de seu próprio movimento. Este se trata, conforme aponta Elkonin (2017), de um processo dialeticamente contraditório. Ou seja, primeiro que não ocorre de maneira progressiva e uniforme, segundo que se caracteriza por processos de negação, retrocesso, interrupções em sua própria continuidade e, ao mesmo tempo, pela constituição de novas formações, de avanços.

Em continuação aos estudos de Vigotski, Leontiev constituiu uma contribuição fundamental, os conceitos de atividade-guia ${ }^{7}$ e atividade acessória. A atividade-guia corresponde aquela que dirige o desenvolvimento das principais mudanças em determinado período, já as atividades acessórias consistem nas diversas atividades que coexistem à primeira, mas que exercem um papel secundário na promoção do desenvolvimento (LEONTIEV, 1978). Sobre esta relação Elkonin (2017, p. 168) sublinha:

[...] quando se fala de atividade principal e de sua importância para o desenvolvimento da criança em um ou outro período, isso não significa, em hipótese alguma, que não exista um desenvolvimento simultâneo em outras direções. A vida da criança em cada período é multifacetada, e as atividades, por intermédio das quais se realiza, são variadas.

Elkonin (2017) chama atenção para a impossibilidade de compreender um período apenas pela estrutura de sua atividade, por suas ações e operações. Ainda que estas sejam importantes, a questão central vincula-se à interação da criança com a realidade a partir de certa atividade, ou seja, a relação da realidade para/com a criança, bem como da criança para/com a realidade. A isto se vincula os significados e sentidos que a criança atribui aos fenômenos que a circundam,

\footnotetext{
${ }^{7} \mathrm{O}$ conceito de atividade-guia pode ser encontrado com diferentes traduções: atividade principal, atividade dominante, atividade rectora, entre outros termos.
} 
as necessidades que surgem a partir de suas diversas relações, os motivos que são constituídos a partir de suas vivências, a reestruturação da consciência, etc.

Ou seja, para Elkonin (2017) a atenção do psicólogo não pode se dirigir apenas a atividade, deve também levar em conta os aspectos da realidade que a orientam. Outra proposição essencial do autor diz respeito à noção de unidade cognitivo-afetiva. Para ele urge a necessidade de superar uma visão dualista que separa ambos os aspectos, isso porque o desenvolvimento psíquico deve ser compreendido como um processo único e integral.

A partir de tais considerações, fica evidente a relevância da compreensão do desenvolvimento psíquico na infância, bem como de sua periodização, por parte da/o psicóloga/o escolar e educacional. Concordamos com Magalhães e Martins (2020, p. 17) quando afirmam que "cabe à psicologia educacional fornecer subsídios das pesquisas sobre o desenvolvimento humano à pedagogia escolar". No entanto, o foco neste artigo diz respeito a uma atividade-guia em particular, a atividade de estudo, atividade-guia da criança em idade escolar.

Temos defendido que entender sobre a atividade de estudo da criança é fundamental para compreendermos a quem se ensina, ou seja, quem é o sujeito estudante e como se desenvolve sua atividade: “A compreensão sobre o conteúdo e a estrutura da atividade principal em cada período é fundamental para pensarmos a organização e a metodologia do ensino” (ASBAHR, 2018, p. 137).

No entanto, o tema da atividade de estudo é pouco desenvolvido nas pesquisas brasileiras cujo referencial é a teoria histórico-cultural, o que pode ser constatado em Puentes (2019) ${ }^{8}$ e em Mendonça e Asbahr (2018), e praticamente ausente nas discussões da psicologia escolar (GUARAGNA, 2020).

\section{Atividade de estudo: formação, desenvolvimento e estrutura}

O propósito desta seção é apresentar de forma breve como a atividade de estudo desenvolve-se, estrutura-se e quais são seus resultados no desenvolvimento da criança. Mas antes disso é importante destacar que a

\footnotetext{
${ }^{8}$ Segundo Puentes (2019),as pesquisas sobre teoria da atividade de estudo são tímidas no Brasil. Um trabalho sobre o estado atual dessas pesquisas não foi realizado até o presente momento em nosso país.
} 
atividade de estudo não é apenas um conceito da psicologia do desenvolvimento, mas também da didática soviética, especialmente desenvolvida no âmbito do Sistema Didático Elkonin-Davidov-Repkin 9 . Segundo Davidov (1996/2020), o conceito de atividade de estudo surge em suas pesquisas com a colaboração de Elkonin e outros autores no final dos anos 50 do século passado em que empreenderam uma série de pesquisas com o objetivo de entender como ocorria a aprendizagem dos estudantes soviéticos a partir de algumas perguntas de pesquisa: o que é atividade de estudo? Como se forma o pensamento teórico? Como o ensino pode ser organizado de maneira a desenvolver o pensamento teórico dos estudantes? Tais perguntas geraram, inclusive, a necessidade de implementar escolas experimentais, como é o caso da escola n.91 de Moscou.

Estes estudos produziram o que hoje conhecemos como Teoria da Atividade de Estudo ${ }^{10}$ e Puentes (2019) propõe uma periodização sobre como o conceito de atividade de estudo foi desenvolvido dos anos 1950 até a atualidade. No entanto, no âmbito deste artigo, focaremos as discussões sobre esta atividade entendida como atividade-guia da criança em idade escolar, ou seja, enfatizaremos a dimensão psicológica desta atividade. Mesmo com essa ressalva, é importante destacar que, em concordância com Puentes (2019), a atividade de estudo precisa ser entendida como "expressão da unidade constitutiva da atividade docente, que inclui tanto o trabalho didático do professor quanto o da autotransformação dos alunos" (p.126).

Buscando compreender a gênese do desenvolvimento da atividade de estudo, os psicólogos soviéticos apontam que a entrada na escola possibilita à criança uma reorganização de sua vida, a qual modifica suas relações interpessoais, sua relação com a realidade e consigo mesma. É a partir do processo de escolarização que a criança pode aprender de forma planejada e

\footnotetext{
${ }^{9}$ Sobre o Sistema Didático Elkonin-Davidov-Repkin, ver Puentes; Longarezzi (2019) e o dossiê sobre o mesmo sistema (volume 5, n.2, 2021) neste periódico, disponível em http://www.seer.ufu.br/index.php/Obutchenie/issue/view/2149.

${ }^{10}$ Sobre a teoria da atividade de estudo, recomendamos as obras de Puentes, Cardoso e Amorim (2020) e Puentes e Mello (2019).
} 
sistematizada as diversas formas de consciência social produzidas historicamente pela humanidade. No entanto, para que isso ocorra, surge como necessidade uma mudança em sua atividade, a criança passa agora a reproduzir ${ }^{11}$ as diferentes formas de atividade humana encarnadas nos vários conhecimentos, sendo esta a atividade de estudo (DAVÍDOV, 1988).

É claro que o processo de aprendizagem não ocorre apenas a partir do estudo, o que faz com que ambos não possam ser identificados, no entanto a aprendizagem se constitui enquanto objeto específico da atividade de estudo. Vale a ressalva, todavia, de que não é meramente a entrada da criança na escola e a aprendizagem que garantem a constituição da atividade de estudo. Davídov (1988) explica que tal atividade possui certa particularidade, já que se constitui a partir de um conteúdo e uma estrutura característica.

Dessa forma, Asbahr (2016) aponta que não é qualquer ação que compõe a atividade de estudo. Ações como a leitura de um texto, cópia da lousa, realização de um exercício etc. podem constituir a atividade de estudo se seus fins forem condizentes aos motivos da atividade, tendo como horizonte a constituição do pensamento teórico.

O estudo, portanto, consiste na atividade em que os sujeitos se apropriam das diferentes formas de consciência social constituídas historicamente pela humanidade, bem como das ações mentais nas quais estes conhecimentos se assentam. Davídov (1988) explica esta proposição a partir da ideia de que o conhecimento possui uma unidade com a atividade cognitiva que a gerou, sendo assim produto (representação da realidade) e processo (ações mentais necessárias à sua apreensão). A partir disso, apreende que o conteúdo da atividade de estudo são os conceitos teóricos ${ }^{12}$ (DAVÍDOV, 1988).

No entanto, o processo de aprendizagem dos conceitos teóricos não ocorre de forma passiva, é necessário que os estudantes realizem determinadas ações. Assim, a fim de desvelar a estrutura da atividade de estudo, Elkonin

\footnotetext{
${ }^{11}$ Importante ressaltar que a utilização do termo reprodução não corresponde a uma mera cópia mecânica, entende-se, na verdade, que neste processo a criança se apropria de tais atividades ao mesmo tempo em que as reelabora.

${ }^{12}$ Estes podem ser científicos, filosóficos, artísticos etc.(DAVÍDOV, 1988).
} 
defendeu a necessidade de compreender a sua unidade de análise, a tarefa de estudo (DAVÍDOV; MÁRKOVA, 1987). Esta engloba o objetivo da ação e as condições para alcançá-la, pois o professor estabelece uma situação-problema de caráter teórico que exige a realização de certas ações por parte do estudante que são necessárias à resolução. Dessa forma, o escolar reproduz o movimento lógico-histórico do conceito, a partir da ascensão do abstrato ao concreto, e se coloca em relação com a necessidade humana que gerou a sua elaboração. Espera-se, assim, superar o verbalismo e as formas mecânicas de apreensão de conhecimentos, bem como vincular os motivos do estudo às necessidades históricas do próprio gênero humano (ASBAHR, 2016).

A partir disso, Davídov e Márkova (1987) assinalam que a estrutura da atividade de estudo ${ }^{13}$ corresponde a: compreensão das tarefas de estudo pelo escolar, a realização das ações de estudo e as ações de controle e avaliação. A fim de se constituir uma atividade integral, os autores apontam que todas estas ações devem estar presentes no processo de estudo do escolar.

A compreensão da tarefa de estudo diz respeito às generalizações teóricas apreendidas, a motivação ao estudo e ao desenvolvimento da autonomia. Já as ações de estudo correspondem aos domínios de passagem das relações gerais às particulares e vice-versa. Por fim, as ações de controle e avaliação vinculam-se à análise das próprias ações do sujeito, bem como de seu processo de aprendizagem (DAVÍDOV; MÁRKOVA, 1987).

Importante ressaltar que

[...] no processo de formação da atividade de estudo, o papel do professor é central, pois é ele quem organiza as tarefas de estudo e ajuda os estudantes na realização das ações de estudo, controle e avaliação. Dessa maneira, o professor paulatinamente cria situações que proporcionem aos estudantes a autonomia na resolução e proposição das tarefas de estudo e a formação da capacidade de estudar (ASBAHR, 2016, p. 180).

\footnotetext{
${ }^{13}$ A estrutura da atividade de estudo foi repensada e reconfigurada ao longo do desenvolvimento de sua investigação. Para verificar tal processo, indica-se a leitura de Puentes (2019).
} 
Percebe-se, assim, que a atividade de estudo não se forma naturalmente, de modo que ao longo de seu processo de constituição espera-se que cada vez mais a criança adquira autonomia, tornando-se sujeito de sua própria atividade. Compreender tal aspecto, além de fazer frente a visões maturacionistas e biologizantes do desenvolvimento, ainda se mostra extremamente relevante ao trabalho da/o psicóloga/o escolar em sua parceria com as/os professoras/es, dado que permite um melhor entendimento acerca do processo de formação da atividade de estudo em cada estudante em particular, o que, por sua vez, possibilita a criação das condições necessárias ao seu desenvolvimento.

Retomando, além do desenvolvimento da autonomia, neste mesmo movimento, também desponta uma neoformação psicológica, a qual corresponde às "bases da consciência e do pensamento teórico e das capacidades psíquicas a elas vinculadas (reflexão, análise e planejamento)” (DAVÍDOV, 1988, p. 176).

Dessa forma, como o conteúdo da atividade de estudo são os conceitos teóricos, é a partir de sua apropriação que tais neoformações são desenvolvidas e a criança passa a estabelecer uma nova relação com a realidade. Isso porque o pensamento teórico se caracteriza por uma existência mediada, refletida e essencial, já que opera com os verdadeiros conceitos, que permitem a compreensão da relação entre universal e singular, possibilitando o desvelamento tanto de seu percurso de formação, quanto de sua inter-relação com os demais conceitos. Os conceitos refletem, portanto, a essência do movimento do objeto (DAVÍDOV, 1988).

A vista disso, é notável que o pensamento teórico se diferencie do pensamento empírico, este último forma uma universalidade abstrata a partir da experiência social, deriva da própria atividade sensorial dos sujeitos. Dessa forma, limita-se à descrição, classificação, esquematização e exposição daquilo que o indivíduo percebe nas manifestações externas dos objetos. Já o pensamento teórico compreende as dependências internas e essenciais do objeto, as quais não são passíveis de observação direta, pois estão presentes nas mediações e em seu próprio movimento de constituição. 
Sintetizando, a atividade de estudo tem como resultado a aprendizagem das ações gerais com os conhecimentos teóricos, que neste processo transformam o psiquismo infantil. Para isso, é necessário que o ensino ocorra a partir do movimento lógico-histórico dos conceitos, que demandam ações de estudo dos sujeitos. E é a partir deste processo de aprendizagem que se torna possível a formação do pensamento teórico.

No entanto, é necessário salientar a impossibilidade de estabelecer uma relação direta e imediata entre as ações de estudo e o desenvolvimento psíquico. Conforme salientam Davídov e Márkova (1987, p. 320, tradução nossa):

o desenvolvimento psíquico não deve deduzir-se diretamente da lógica da atividade de estudo. Durante sua formação há que revelar e criar as condições para que a atividade adquira um sentido pessoal, converta-se em fonte de autodesenvolvimento do indivíduo, do desenvolvimento multilateral de sua personalidade, na condição de inclusão na prática social.

Isso significa que para a compreensão da atividade de estudo em sua integralidade é insuficiente a análise da eficácia das ações de estudo, também se mostra essencial desvelar seu conteúdo interno examinando-se, especialmente, a constituição dos motivos para o estudo, a compreensão que a criança possui da finalidade da atividade e aquilo que estabelece a relação entre ambos, o sentido pessoal atribuído a esta atividade-guia.

Para Leontiev (1978), ao longo do processo de escolarização, é possível que os motivos vinculados ao estudo se modifiquem. Ou seja, por meio do ensino é possível transformar a curiosidade infantil em motivos que se vinculam à própria aprendizagem. O autor explica que, recorrentemente, no período inicial da escolarização os motivos para a atividade de estudo encontram-se relacionados às vivências mais imediatas e que estes nem sempre são conscientizados pelos estudantes. No entanto, estes podem vir a se constituir enquanto geradores de sentido.

Tal pontuação é de extrema relevância, pois o processo de conscientização dos conhecimentos é dependente do sentido. Isso significa que para que o processo de aprendizagem não ocorra de maneira apenas formal, é imprescindível que os 
motivos vinculados sejam cognitivos. Entende-se, assim, que com a formação de novos motivos durante o estudo e, portanto, de novos sentidos, são criadas novas possibilidades ao intelecto, já que os motivos impulsionam o estudo e são responsáveis pela forma como os conhecimentos serão conscientizados. Concluise, a partir disso, que não basta que os significados dos conhecimentos sejam adquiridos pelos estudantes, na verdade, estes devem ocupar um lugar em suas vidas. Ressaltamos que a compreensão do processo de formação de motivos para o estudo é tema central à atuação da psicologia na escola, haja vista que uma das principais queixas que nos chegam do cotidiano escolar é justamente a falta de interesse e motivação dos estudantes.

A questão é que os motivos formam-se na vida real da criança, em vinculação à totalidade de sua esfera motivacional, ou seja, não são intrínsecos, naturais. De modo que Davídov e Márkova (1987) chamam a atenção da necessidade de, por meio da prática pedagógica, criar condições para que a atividade de estudo adquira sentido aos estudantes e concluem:

[...] o ensino não pode ser reduzido à transmissão de conhecimentos, a elaboração e aperfeiçoamento das ações e operações, senão que é, fundalmentalmente, a formação da personalidade do aluno, o desenvolvimento da esfera que determina seu comportamento (valores, motivos, objetivos, etc.) (DAVÍDOV; MÁRKOVA, 1987, p. 333).

Ao trabalho da/o psicóloga/o escolar deve-se ter claro, portanto, que a atividade de estudo não corresponde apenas ao domínio de conteúdos escolares, tampouco a realização de ações de estudo, ainda que estes se façam relevantes, ela diz respeito ao processo de reestruturação da personalidade da criança. Conforme aponta Asbahr (2020, p. 86):

a apropriação de conhecimentos teóricos não pode ser um fim em si mesma, mas mediação para que os sujeitos, ao saírem dos limites do conhecimento cotidiano, possam compreender a realidade como totalidade (o que abarca suas contradições e historicidade), e, ao entendê-la, possam construir as condições para a emancipação humana da sociedade do capital. 
$\mathrm{Ou}$ seja, a atividade de estudo se constitui enquanto o meio pelo qual a criança apropria-se das diferentes formas de consciência social, tornando possível a reestruturação de seu psiquismo e transformação de sua personalidade, o que, por sua vez, oportuniza que o escolar desenvolva uma nova forma de relação com a realidade, na qual esta última adquire um grau maior de inteligibilidade. Dessa forma, tem em si como potência que a criança se torne cada vez mais autônoma.

Por fim, chama-se atenção para o papel da coletividade na formação da atividade de estudo. É fato conhecido que desde a idade pré-escolar a criança já se encontra inserida em um coletivo infantil, todavia sob a base do estudo ocorrem transformações nas relações entre as crianças tendo em vista a aprendizagem compartilhada (BOZHOVICH, 1985).

A própria assimilação de conhecimentos possui em seu íntimo a relação e colaboração com o outro, seja por meio da comunicação entre pessoas, seja por meio da comunicação com o gênero humano expresso em ideias fixadas nos instrumentos da cultura (DAVÍDOV; MÁRKOVA, 1987). Assim, o caráter coletivo adquire importância decisiva, ultrapassando inclusive os limites do estudo. Conforme aponta Bozhovich (1985, p. 234-235, tradução nossa), "os escolares começam a viver uma vida conjunta, variada, plena de interesses, aspirações e tristezas comuns".

No entanto, na contramão de tal compreensão, a forma de sociabilidade desenvolvida no sistema do capital é hegemonicamente competitiva e individualista (MESQUITA, 2018). Tal forma de relação é responsável pela fragmentação da unidade social entre grupos, sustentando, assim, uma alteridade ontonegativa. Tal conceito expressa a ideia de que o outro passa a ser compreendido como uma ameaça, gerador de sofrimentos, torna-se objeto de afetos agressivos. Esta forma de sociabilidade não ocorre apenas nas formas mais gerais de relação entre os sujeitos, mas também se expressa na educação escolar (MESQUITA, 2018).

Nas palavras de Mesquita (2018, p. 12):

[...] individualismo e competição são ensinados socialmente como dados da sociabilidade, hábitos de comportamento e 
também como contexto do desenvolvimento de valores. A valoração do desejo individual como mais importante que o coletivo e a valoração das outras pessoas como adversárias ou empecilhos à realização dos desejos do "Eu" são ensinadas socialmente e compõe parte das formas de recomposição ideológica na sociedade do capital. A forma de ensino desses valores é sub-reptícia, acontece direta e indiretamente, como desdobramento de um certo tipo de sociabilidade, uma que individualiza capacidades, tarefas e a própria história de desenvolvimento, que cria laços interpessoais conflitivos.

Conforme o autor explica, tal forma de relação entre sujeitos foi forjada a partir de processos históricos amplos e vincula-se à própria constituição da modernidade. Entretanto, a escola corresponde a uma instituição que pode refletir conscientemente sobre os tipos de sociabilidade que cria em seu interior, engajando-se em um movimento contrário e tensionando tais relações (MESQUITA, 2018). A esta lógica vincula-se também o trabalho da/o psicóloga/o escolar que ao compreender, defender e orientar sua atuação tendo em vista a constituição da atividade de estudo em seu caráter coletivo adquire a possibilidade de fazer frente à reprodução acrítica da sociedade do capital no interior da educação escolar.

A partir disso, entende-se inclusive que no interior da educação escolar não basta compreender o que se ensina, de que forma se ensina e a quem se ensina, mas também o para quê se ensina (ASBAHR, 2020). Ou seja, é necessária a compreensão da dimensão ética, tanto para o trabalho da/o psicóloga/o escolar, quanto dos educadores, tendo como perspectiva a formação da consciência de classe e a constituição de um projeto coletivo de sociedade organizada a partir dos interesses da própria classe trabalhadora (ASBAHR, 2020).

Conforme já assinalado anteriormente, a atividade de estudo não possui uma finalidade em si mesma. Isso significa que sua constituição não se vincula à preparação de sujeitos para o vestibular ou para o mercado de trabalho (PARO, 2001). Da mesma forma, também não visa a formação de sujeitos que aprendem de maneira apenas formal, verbalizando com precisão os conhecimentos, mas sem conseguir colocá-los em movimento em sua relação com a realidade (ASBAHR, 2020). Dessa forma, a atividade de ensino e de estudo devem se constituir a fim de que os 
estudantes possam se humanizar no próprio processo de conhecer e compreendam que o mundo é passível de transformação. Tem em vista, portanto, que os sujeitos reconheçam em si, nos outros e nas produções e nos objetos da cultura sua essência humana, criando condições para um processo de emancipação coletiva ${ }^{14}$.

No sentido contrário, a escola atual, a qual compreende a educação como mercadoria, fazendo com que esta se adapte a lógica e as exigências do capital, estabelece de forma geral à vida e, consequentemente, também à escola uma relação temporal que se manifesta a partir da aceleração (MAIA, 2016). Tal característica temporal se expressa no cotidiano escolar, por exemplo, a partir de cortes e abandonos de conteúdo, da disseminação da ideia de eficácia vinculada ao menor "gasto" de tempo, a valorização de ferramentas tecnológicas que visam a mera obtenção de eficiência, a inserção da lógica do ensino apostilado e a rapidez no ensino de conteúdos que visem a preparação para testes padronizados, entre outros (MAIA, 2016).

Fica clara a divergência de tal aceleração com a formação e desenvolvimento da atividade de estudo, a qual demanda tempo, um tempo que não se vincula a mera eficácia produtiva, mas ao processo de autotransformação do estudante e a uma educação integral, ligada a apropriação de um grande leque de conhecimentos produzidos pela humanidade, ao debate, ao diálogo, a formação política, etc. Para tanto, são necessárias condições objetivas que assegurem aos estudantes a possibilidade de desenvolverem a atividade de estudo, ou seja, condições que garantam às crianças e adolescentes sua permanência nas instituições de ensino, bem como materiais, livros, espaços etc. necessários à organização do estudo. $\mathrm{O}$ que implica, por sua vez, o cuidado, a criação e a luta por parte da/os psicólogas/os escolares por tais condições, constituindo-se assim como princípio teórico e político de sua atuação.

Neste sentido, Lima e Sekkel (2019) fazem uma importante análise acerca das condições concretas existentes na educação escolar brasileira que (im)possibilitam o

\footnotetext{
${ }^{14}$ Salientamos aqui a necessidade de compreender o processo de emancipação humana não enquanto uma conquista meramente do indivíduo singular, mas da coletividade. Para uma melhor compreensão indica-se Marx (2010)
} 
desenvolvimento da atividade de estudo. As autoras salientam que entender tal aspecto demanda a análise de como são valorizados os conhecimentos escolares, qual projeto de escola está preconizado socialmente e sob quais condições sociais, econômicas e políticas se assenta a atividade de ensino.

Em síntese, os processos históricos que marcam o Brasil se caracterizam por dinâmicas de "exploração, exclusão, sobreposição de interesses individuais aos coletivos, violência e intenso conservadorismo na política, na estrutura social e na cultura" (LIMA; SEKKEL, 2019, p. 14). Dessa forma, tal particularidade não se faz diferente no âmbito da educação escolar, que hegemonicamente cumpriu e cumpre o papel de manutenção da mesma ordem societária. O que se expressa na desvalorização do professor, na desqualificação dos conhecimentos escolares e, inclusive, na depreciação da própria escola (LIMA, SEKKEL, 2019).

A partir disso, apontam que a atual crise social vivenciada pode se constituir enquanto um chamamento à revitalização de uma utopia revolucionária e à transformação do modo atual de produção e reprodução da vida. Para tanto, no campo da educação concluem que:

[...] em tempos nos quais a capacidade criativa e inventiva dos seres humanos é indispensável para a batalha contra a barbárie, discussões sobre como podemos forjar processos sociais e escolares que favoreçam o desenvolvimento da atividade de estudo é um caminho próspero para os profissionais que atuam em contextos educativos (LIMA; SEKKEL, 2019, p. 22).

À vista disso, torna-se claro que a atividade de estudo pode ser uma importante "ferramenta" de combate e de compreensão do fracasso escolar, já que traz em si a possibilidade de pensar e orientar formas de superação do mesmo, tornando-se, assim, um conceito central ao trabalho da/o psicóloga/o escolar. Isso porque, conforme apontado anteriormente, a atividade de estudo possui sua gênese e desenvolvimento nas relações reais que se constituem na educação escolar. Permite, portanto, colocar em movimento aquilo que até então se encontrava cristalizado, tornando-se relevante para a constituição de práticas não-patologizantes e não-culpabilizantes. 


\section{Por uma psicologia escolar concreta: algumas considerações finais}

Temos como premissa que o trabalho da/o psicóloga/o escolar deve ter em vista contribuir para o processo de humanização e emancipação dos indivíduos. Assim, concordamos com Meira (2003) acerca da proposição de que a finalidade da psicologia na educação deve estar direcionada para que a escola cumpra sua função social:

[...] propomos que a finalidade da Psicologia Escolar situa-se no compromisso claro com a tarefa de construção de um processo educacional qualitativamente superior. Portanto, sua função social não poderia ser outra: contribuir para que a escola cumpra de fato seu papel de socialização do saber e da formação crítica. (MEIRA, 2003, p.57, grifos da autora).

Nesta perspectiva, recuperando a defesa feita no início do texto, de que a atividade de estudo é conceito fundamental à atuação da psicologia escolar fundamentada na psicologia histórico-cultural, sustentamos que analisar a aprendizagem das crianças (sempre em sua relação com a atividade de ensino docente) a partir da estrutura e do desenvolvimento da atividade de estudo traz elementos fundamentais para uma compreensão concreta do desenvolvimento infantil. Ou seja, permite que a/o psicóloga/a escolar possa investigar, junto com a equipe docente da escola, porque uma criança não está aprendendo e quais são as condições de ensino que precisam ser criadas para superar as dificuldades encontradas. A psicologia escolar pode colocar-se, assim, a serviço do serviço que a escola precisa fazer: garantir que todas as crianças possam se apropriar das formas mais desenvolvidas da consciência social.

Ou seja, a psicologia na escola pode e deve trazer elementos para pensarmos junto com professoras e professores sobre a organização de um ensino promotor do desenvolvimento. Guardando as devidas especificidades das áreas e objetos de atuação e conhecimento da psicologia e da pedagogia, já elucidadas por Rubinstein (1976) ${ }^{15}$, cabe à psicologia na escola elucidar

${ }^{15}$ Citação do autor: "Consideramos que o mais importante para a prática das tarefas de
investigação psicológica é descobrir o conteúdo psicológico interno da atividade humana o 
quais são as leis psicológicas do desenvolvimento e da aprendizagem infantil que a/o professor/a deve levar em conta.

Magalhães e Martins (2020) sintetizam estas relações entre psicologia e educação, defendendo que a psicologia educacional deve estar subordinada à pedagogia escolar, tese com a qual concordamos: "[...] ao instrumentalizar a atividade docente teórico-metodologicamente, no que tange aos preceitos psicológicos implicados na aprendizagem, é que a psicologia educacional corrobora com o ato de se ensinar" (p.9).

Neste sentido, para além da denúncia da medicalização e da individualização das questões educacionais, com as quais compartilhamos, defendemos uma atuação em parceria com professoras/es, funcionárias/os, gestoras/es, familiares e estudantes que revelem os potenciais para a aprendizagem de todos os envolvidos. Temáticas como aprendizagem, desenvolvimento, formação de motivos, desenvolvimento da atenção, da memória e das demais funções psicológicas superiores, a questão do sentido da atividade pedagógica e sua relação com as vivências da escola de estudantes e professoras/es engendram-se na compreensão da atividade de estudo e são fundamentais à atuação crítica da psicologia na escola.

Por fim, salientamos que as ideias apresentadas acerca da atividade de estudo não se constituem enquanto algo definitivo. Trata-se de um conceito que passou e ainda passa por diversas transformações, o que mostra a necessidade de avançarmos também na investigação de suas peculiaridades no contexto educacional brasileiro. A isto se vincula a compreensão de que o trabalho da/o psicóloga/o escolar não pode ser entendido como uma mera aplicação da teoria, este condiz, na verdade, com um movimento criativo, que busque de fato promover uma unidade entre teoria e prática, na qual a teoria orienta a ação, do mesmo modo que a prática proporciona novos desvelamentos da realidade.

qual se manifesta e forma o homem, suas qualidades psíquicas. Para a prática pedagógica, a tarefa será descobrir o conteúdo psicológico interno da atividade da criança em curso no qual se realiza seu desenvolvimento e se formam suas qualidades psíquicas". (RUBINSTEIN, 1976, p. 201, grifos do autor, tradução nossa) 


\section{Referências}

ASBAHR, F. S. F. Idade escolar e atividade de estudo: educação, ensino e apropriação dos sistemas conceituais. In: MARTINS, L. M.; ABRANTES, A. A.; FACCI, M. G. D. Periodização Histórico-Cultural do Desenvolvimento Psíquico. Campinas: Autores Associados, 2016.

ASBAHR, F. S. F. Atividade de estudo, coletivos infantis e o problema da transmissão escolar do conhecimento científico, filosófico e artístico. In: PASQUALINI, J. C.; TEIXEIRA, L.A.; AGUDO, M.M. (Orgs.). Pedagogia histórico-crítica: legado e perspectivas. 1ed.Uberlândia: Navegando, 2018, v. 01, p. 135-147. Disponível em: https://www.editoranavegando.com/livro-juliana-1.

ASBAHR, F. S. F. A pesquisa sobre formação de pensamento teórico. Revista Simbio-Logias, v. 12, n. 17, p. 85-102, 2020. Disponível em https://www.ibb.unesp.br/Home/ensino/departamentos/educacao/a_pesquisa_sobr e_formacao_de_pensamento.pdf.

ASBAHR, F. S. F.; LOPES, J. S. "A culpa é sua”. Revista Psicologia USP, v. 17, n. 1, p. 53-73, 2006. DOI: https://doi.org/10.1590/S0103-65642006000100005.

BOZHOVICH, L. I. La personalidad y su formación en la idad infantil. Habana: Editorial Pueblo y Educación, 1985.

DAVÍDOV, V. V. La enseñanza escolar y el desarrollo psíquico: investigación teórica y experimental. Moscou: Editorial Progresso, 1988.

DAVÍDOV, V. V. Atividade de estudo e aprendizagem desenvolvimental. (1996). In.: PUENTES, R.V.; CARDOSO, C. G. C. ; AMORIM, P. A. P. (Orgs.) . Teoria da atividade de estudo: Contribuições de D. B. Elkonin, V. V. Davidov e V. V. Repkin (Livro I). $2^{\text {a }}$ Edição. 2. ed. Curitiba: Editora CRV, 2020. 1996/2020.

DAVÍDOV, V. V.; MÁRKOVA, A. La concepción de la actividad de estudio de los escolares. In: DAVÍDOV, V.; SHUARE, M. (Org.) La psicologia evolutiva y pedagógica en la URSS. Moscou: Editorial Progreso, 1987, p. 316-337.

ELKONIN, D. B. Sobre o problema da periodização do desenvolvimento psíquico da infância. In: LONGAREZI, A. M.; PUENTES, R. V. (Org). Antologia: livro I. Uberlândia, EDUFU, 2017.

FACCI, M. G. D. Valorização ou esvaziamento do trabalho do professor? Um estudo crítico-comparativo da teoria do professor reflexivo, do construtivismo e da psicologia vigotskiana. Campinas: Autores Associados, 2004.

FACCI, M.G.D.; ANACHE, A.A.; CALDAS, R.F.L. (orgs). Por que a Psicologia na educação? Em defesa da emancipação humana no processo de escolarização. (Volume 1). Curitiba: CRV, 2021. DOI: https://doi.org/10.24824/978652510695.3. 
FACCI, M. G.; MEIRA, M. E.; TULESKI, S. C. A exclusão dos “incluídos”: uma crítica da psicologia da educação à patologização e medicalização dos processos educativos. Maringá: Eduem, 2011.

GUARAGNA, C. S. . Estado da arte das produções brasileiras sobre orientação à queixa escolar a partir da psicologia histórico-cultural. Relatório de Iniciação Científica (Fapesp), Bauru, 2020.

LEONTIEV, A. O desenvolvimento do psiquismo. Lisboa: Horizonte Universitário, 1978.

LIMA, C. P.; SEKKEL, M. C. Notas sobre as relações entre escola, família e sociedade na formação da atividade de estudo. Obutchénie: Revista de Didática e Psicologia Pedagógica, v. 3, n. 3, p. 1-31, 2019. DOI: https://doi.org/10.14393/OBv3n3.a2019-51705.

LONGAREZI, A.M.; PUENTES, R. V. (Org.) Ensino Desenvolvimental: vida, pensamento e obra dos principais representantes russos - Livro I.

Uberlândia: Edufu, 2013.

MACHADO, A. M. Avaliação psicológica na educação: mudanças necessárias. In: TANAMACHI, E. R.; SOUZA, M. P. R.; ROCHA, M. Psicologia e Educação: desafios teórico-práticos. São Paulo: Casa do Psicólogo, p. 143-167, 2000.

MAGALHÃES, G. M.; MARTINS, L. M. Onze teses sobre a relação entre psicologia educacional e pedagogia escolar. Revista Educação em Questão, v. 58, n. 55, p. 1-21, 2020. DOI: https://doi.org/10.21680/1981-1802.2020v58n55ID19150.

MAIA, A. F. O tempo e a gestão na educação: elementos de uma análise a partir da Teoria Crítica. RPGE: Revista online de Política e Gestão Educacional, v. 20, n. 03, p. 528-546, 2016. DOI: https://doi.org/10.22633/rpge.v20.n3.9758.

MARX, K. Sobre a questão judaica. Tradução Nélio Schneider. São Paulo: Boitempo, 2010.

MARX, K. Teses sobre Feuerbach (1845). In: FRIGOTTO, G.; CIAVATTA, M.; CALDART, R. S. História, natureza, trabalho e educação. $1^{\text {a }}$ ed. São Paulo: Expressão Popular, p. 67-71, 2020.

MEIRA, M. E. M. Psicologia escolar: pensamento crítico e práticas profissionais. In: TANAMACHI, E. R.; SOUZA, M. P. R.; ROCHA, M. Psicologia e Educação: desafios teórico-práticos. São Paulo: Casa do Psicólogo, p. 35-71, 2000.

MEIRA, M. E. M. Construindo uma concepção crítica de Psicologia Escolar: contribuições da pedagogia histórico-crítica e da psicologia histórico-cultural. In.: MEIRA, M.E.M.; ANTUNES; M.A.M. (orgs). Psicologia escolar: teorias críticas. São Paulo: Casa do psicólogo, p. 13-77, 2003. 
MENDONÇA, A.B.J.; ASBAHR, F. S. F. Atividade de estudo e sentido pessoal: uma revisão teórica. Obutchénie: Revista de Didática e Psicologia Pedagógica, v. 2, n. 3, p. 780-800, 2018. DOI: https://doi.org/10.14393/OBv2n3.a2018-47450.

MENEGHETTI, F. K. O que é um ensaio-teórico? Revista de Administração Contemporânea [online]. v. 15, n. 2, pp. 320-332, 2011. DOI:

https://doi.org/10.1590/S1415-65552011000200010.

MESQUITA, A. M. de. A formação psicológica de valores morais no contexto da sociabilidade competitiva e individualista na educação: apontamentos para a atividade pedagógica. Tese (Doutorado em Educação) - Faculdade de Filosofia e Ciências, Universidade Estadual Paulista (Unesp), Marília, 2018. Disponível em: https://www.marilia.unesp.br/Home/Pos-

Graduacao/Educacao/Dissertacoes/mesquita_am_do_mar.pdf.

PARO, V. H. Parem de preparar para o trabalho!!! Reflexões acerca dos efeitos do neoliberalismo sobre a gestão e o papel da escola básica. In: PARO, V. H. Escritos sobre educação. São Paulo: Xamã, 2001.

PATTO, M. H. S. Introdução à Psicologia Escolar. São Paulo: T. A. Queiroz, 1981.

PATTO, M. H. S. A produção do fracasso escolar: histórias de submissão e rebeldia. São Paulo: Casa do Psicólogo, 1999.

PRESTES, Z. R. Quando não é a mesma coisa: análise de traduções de Lev Semionovitch Vigotski no Brasil: repercussões no campo educacional. 2010. $295 \mathrm{f}$. Tese (Doutorado em Educação) - Universidade de Brasília, Brasília, 2010. Disponível em: https://repositorio.unb.br/handle/10482/9123.

PUENTES, R. V. Sistema Elkonin Davidov-Repkin: gênese e desenvolvimento da Teoria da Atividade de Estudo - TAE (1959-2018). In: PUENTES, R. V.;

LONGAREZI, A. M. (Orgs.) Ensino Desenvolvimental. Sistema Elkonin-Davidov. Campinas: Mercado de Letras - Uberlândia: Edufu, 2019.

PUENTES, R.V.; LONGAREZI, A. M.. Ensino desenvolvimental: vida, pensamento e obra dos principais representantes russos - Livro II. Uberlândia: Edufu, 2016.

PUENTES, R.V.; LONGAREZI, A. M.. Ensino desenvolvimental: vida, pensamento e obra dos principais representantes russos - Livro III. Uberlândia: Edufu e Paco Editorial, 2019.

PUENTES, R.V.; MELLO, S. A. (Org.). Teoria da Atividade de Estudo: contribuições de pesquisadores brasileiros e estrangeiros (Livro II). 1. ed. Uberlândia: Edufu, 2019. 
PUENTES, R.V.; CARDOSO, C. G. C. ; AMORIM, P. A. P. (Orgs.) . Teoria da atividade de estudo: Contribuições de D. B. Elkonin, V. V. Davidov e V. V. Repkin (Livro I). $2^{\text {a }}$ Edição. 2. ed. Curitiba: Editora CRV, 2020.

RUBINSTEIN, S.L. Problemas de psicologia general. Mexico- DF: Grijaldo, 1976.

SAVIANI, D. Escola e democracia. São Paulo: Autores Associados, 2008.

SHUARE, M. A psicologia soviética: meu olhar. São Paulo: Terracota editora, 2017.

SOUZA, M.P.R. A queixa escolar na formação de psicólogos: desafios e perspectivas. In: TANAMACHI, E. R.; SOUZA, M. P. R.; ROCHA, M. Psicologia e Educação: desafios teórico-práticos. São Paulo: Casa do Psicólogo, p. 105-167, 2000.

SOUZA M.P. R.; MACHADO, A. M. (Org.). Psicologia Escolar: em busca de novos rumos. São Paulo: Casa do Psicólogo, 1997.

SOUZA, M.P.R; SILVA, S.M.C; YAMAMOTO, K. (Org.). Atuação do psicólogo na Educação Básica: concepções, práticas e desafios. Uberlândia: Edufu, 2014

TANAMACHI, E.R. Mediações teórico-práticas de uma visão crítica em psicologia escolar. In: TANAMACHI, E. R.; SOUZA, M. P. R.; ROCHA, M. Psicologia e Educação: desafios teórico-práticos. São Paulo: Casa do Psicólogo, p. 73-103, 2000.

TANAMACHI, E. R.; MEIRA, M. E. A atuação do Psicólogo como Expressão do Pensamento Crítico em Psicologia e Educação. In: MEIRA, M. E.; ANTUNES, M. A. Psicologia Escolar: Práticas Críticas. São Paulo: Casa do Psicólogo, 2003.

VIGOTSKI, L. S.. Manuscrito de 1929 (Psicologia concreta do homem). Educação \& Sociedade, vol. 21, n. 71, p. 21-44, 2000.

VIGOTSKI, L. S. A construção do pensamento e da linguagem. $2^{\mathrm{a}}$ ed, São Paulo: Martins Fontes, 2009.

VYGOTSKY, L. S. Aprendizagem e desenvolvimento intelectual na idade escolar. In: VYGOTSKY, L. S.; LURIA, A. R.; LEONTIEV, A. N. Linguagem, desenvolvimento e aprendizagem. $5^{\mathrm{a}}$ ed. São Paulo: Editora Ícone, p. 103-117, 1988.

VYGOTSKI, L. S. Obras Escogidas IV. Madrid: Machado Nuevo Aprendizaje, 2012.

Recebido em novembro de 2021.

Aprovado em dezembro de 2021. 